\title{
MENINGKATKAN MINAT DAN HASIL BELAJAR FISIKA MELALUI MEDIA PEMBELAJARAN PHYSICS COURSEWARE
}

\author{
Mubarus Naibaho \\ SMP Negeri 85 Jakarta \\ Email: mubaroes@gmail.com
}

\begin{abstract}
Abstrak
Arus listrik didefinisikan sebagai arah aliran muatan positif dari kutub positif ke kutub negatif dipahami secara semu dan bayangan. Banyaknya rumus dan fakta-fakta memberi kesan rumit dan membosankan. Persiapan, pelaksanaan, dan penyelesaian praktek sangat membutuhkan tenaga dan waktu yang banyak, sehingga pemanfaatan alat-alat laboratorium juga menjadi salah satu penyebab lemahnya pemahaman siswa kelas IX/2 di SMP Negeri 85 Jakarta. Media pembelajaran dengan program Ms. Power Point. selain sebagai media presentasi, program ini juga menyediakan berbagai fasilitas untuk berkreasi, mengolah, dan menginput file audio, file video maupun animasi. Program ini dapat dikembangkan sebagai perangkat ajar fisika (Physics Courseware) untuk meningkatkan pemahaman, ketertarikan dan minat siswa terhadap pelajaran fisika. Kesulitan dalam pemahaman materi dengan adanya media pembelajaran tersebut kemudian dilakukan suatu tindakan yang dilaksanakan pada semester ganjil tahun pelajaran 2016/2017 dengan 2 siklus. Tindakan pada siklus I dan siklus II melalui pemanfaatan Media Pemanfaatan Physic Courseware terlihat ada perubahan minat dan hasil belajar yang terjadi. Indikator keberhasilan penelitian dilihat dari indikator kinerja yakni apabila semua aspek yang diamati telah mencapai $85 \%$ atau lebih. Setelah seluruh tindakan dilakukan, dan dari hasil pengamatan, penilaian, dan pembahasan, dinyatakan bahwa: pemanfaatan media physics courseware sebagai media pembelajaran fisika dapat meningkatkan minat dan hasil belajar siswa.
\end{abstract}

Kata Kunci: Minat belajar, arus listrik, physics courseware

\begin{abstract}
Electric current is defined as the flow direction of positive charge from the positive pole to the negative pole that is understood in imaginary. Numbers of formulas and facts give complicated and boring impression. Preparation, implementation, and completion of practice require a lot of energy and time, so the use of equipment in the laboratory is also one of the causes for the weak understanding of grade IX / 2 students at SMP Negeri 85 Jakarta. Ms. Power Point, as a presentation medium, also provides various facilities for creating, processing, inputting audio files, video files, and even animation. This program was developed as a physics teaching tool (Physics Courseware) to increase students' understanding and interest in physics lessons. The difficulty in understanding the material with the existence in learning media was then carried out in an action which was implemented in the odd semester of the 2016/2017 academic year with 2 cycles. Actions in cycle I and cycle II were through the use of Media Physic Courseware and it was seen that there was a change in interest and learning outcomes. The research success indicator was seen from the performance indicator, that was if all the observed aspects had reached $85 \%$ or more. After all actions taken, and from the result of observation, assessment, and discussion, it was concluded that the use of physics courseware can increase student interest and learning outcomes.
\end{abstract}

Keywords: Learning interest, electric current, physics courseware

\section{PENDAHULUAN}

Dinamika dunia pendidikan yang sangat beragam, tentu saja memiliki dampak terhadap kualitas belajar siswa di sekolah.
Faktor dominan yang mempengaruhi kualitas belajar siswa yaitu faktor yang berasal dari dalam diri siswa (faktor internal) dan faktor yang berasal dari luar 
faktor eksternal [1]. Faktor internal di antaranya adalah minat, bakat, motivasi, dan tingkat intelegensi. Sedangkan faktor eksternal di antaranya adalah faktor metode pembelajaran dan lingkungan.

Pendidikan fisika harus menjadikan siswa tidak sekedar tahu (to know) dan hafal (to memorize) tentang konsep-konsep fisika saja, melainkan harus menjadikan siswa untuk mengerti, menguasai dan memahami (to understand) konsep-konsep tersebut dan menghubungkan suatu konsep dengan konsep lain [2]. Akan tetapi sebagian siswa merasa kesulitan dalam mempelajari fisika, hal ini disebabkan karena Fisika lebih memerlukan pemahaman dari pada penghafalan dan kebanyakan siswa merasa kesulitan terhadap teori serta terjebak dalam pemahaman rumus. Di antara sekian banyak media yang digunakan salah satunya adalah penggunaan program $M s$. Power Point. Karena selain sebagai media presentasi, program ini juga menyediakan berbagai fasilitas untuk berkreasi, mengolah, dan mengimput file audio maupun animasi. Program ini dapat dikembangkan sebagai perangkat ajar fisika atau media (Physics Courseware) sebagai upaya meningkatkan pemahaman, ketertarikan dan minat siswa terhadap pelajaran fisika.

Media atau alat alat penunjang, proses pembelajaran akan memberikan pandangan bahwa guru atau instruktur bukanlah satusatunya sumber belajar [3]. Media dapat mewakili apa yang kurang mampu guru ucapkan melalui kata-kata atau kalimat tertentu. Selain itu penggunaan media pendidikan diharapkan dapat mempertinggi proses belajar siswa dalam pengajaran yang pada akhirnya diharapkan dapat mempertinggi hasil belajar yang dicapai [4].
Tujuan dari penelitian ini untuk mengetahui kebermanfaatan penerapan media Physics Courseware dalam pembelajaran fisika untuk meningkatkan minat dan hasil belajar siswa setelah melakukan tindakan pada materi arus listrik.

Menurut [5], menjelaskan bahwa minat adalah suatu rasa lebih suka dan rasa ketertarikan pada suatu hal atau individu, tanpa ada yang menyuruh. Minat pada dasarnya adalah penerimaan akan suatu hubungan antara diri sendiri dengan sesuatu di luar diri. Menurut [6], menyatakan bahwa ada beberapa faktor yang mempengaruhi minat belajar diantaranya yaitu: (1) Faktor yang ada pada diri organisme itu sendiri yang kita sebut faktor individual. (2) Faktor yang ada di luar individu yang kita sebut faktor sosial.

Prestasi belajar sendiri diartikan sebagai tingkat keberhasilan siswa setelah menempuh proses pembelajaran tentang materi tertentu, yakni tingkat penguasaan, perubahan emosional, atau perubahan tingkah laku yang dapat diukur dengan tes tertentu dan diwujudkan dalam bentuk nilai atau skor. Apabila siswa memiliki prestasi belajar yang optimal, berarti siswa tersebut memiliki minat belajar yang tinggi.

Menurut [7], menyatakan secara umum media berasal dari bahasa latin ${ }^{3}$ Medium' yang secara harfiah berarti tengah, perantara atau pengantar [8], menyatakan bahwa media merupakan wahana penyalur informasi belajar atau penyalur pesan. Menurut [9], menyatakan bahwa media adalah berbagai jenis komponen dalam lingkungan siswa yang dapat merangsang untuk belajar. Melalui proses komunikasi ini, pesan atau informasi dapat diserap oleh orang lain. Menurut [10], menjelaskan bahwa ada beberapa definisi tentang media pendidikan atau media pembelajaran, diantaranya yaitu Association For 
Education And Communication Tehnology AECT kemudian mendefinisikan media sebagai segala bentuk yang dipergunakan untuk suatu proses penyaluran informasi. Menurut [11] A Medium, concerved is any person, material or event that establishs condition which enable the learner to acquire knowledge, skill and attitude. Menurut Gerlach secara umum, media itu meliputi orang, bahan peralatan atau kegiatan yang menciptakan kondisi yang memungkinkan siswa memperoleh pengetahuan, keterampilan, dan sikap.

Menurut [12], mendefinisikan media sebagai semua bentuk perantara yang dipakai orang penyebar ide, sehingga ide atau gagasan itu sampai pada penerima. Melalui penggunan media pembelajaran diharapkan dapat mempertinggi kualitas proses belajar mengajar yang pada akhirnya dapat mempengaruhi prestasi dan minat belajar siswa. Physic Courseware merupakan sebuah piranti lunak atau program komputer yang didesain untuk digunakan sebagai media pembelajaran fisika dalam rangka meningkatkan minat belajar siswa pada suatu materi tertentu. Menurut [13], menjelaskan bahwa pada hakekatnya, Physic Courseware termasuk media pembelajaran yang dibuat menggunakan aplikasi program Powerpoint. Program Powerpoint adalah program aplikasi presentasi yang merupakan salah satu program aplikasi di bawah Microsoft Office.

Penggunaan perangkat komputer sebagai media pengajaran sendiri dikenal dengan nama pengajaran dengan bantuan komputer atau Computer Assisted Instruction (CAI), yaitu penggunaan komputer secara langsung oleh guru kepada siswa untuk menyampaikan isi pelajaran, memberikan latihan-latihan dan mengetest kemajuan belajar siswa. Dan bisa digolongkan sebagai salah satu dari aplikasi $C A I$ tersebut dalam dunia pendidikan adalah Physics Courseware [8]. Menurut [14], menyatakan bahwa: interaksi siswa dan guru dibangun atas dasar empat unsur, yaitu : tujuan, bahan, metode, alat dan penilaian.

\section{METODE}

Metode penelitian ini adalah Classroom Action Research atau Penelitian Tindakan Kelas (PTK), merupakan suatu bentuk kajian yang bersifat reflektif oleh pelaku tindakan yang dilakukan untuk meningkatkan kemantapan rasional dan tindakan mereka dalam melaksanakan tugas, memperdalam terhadap tindakantindakan yang dilakukan, serta memperbaiki kondisi dimana praktik pembelajaran tersebut dilakukan.

Teknik Pengumpulan Data, sumber data penelitian ini adalah siswa dan data siswa kelas IX semester II SMP Negeri 85 Jakarta Tahun 2016/2017. Jenis data yang digunakan dalam penelitian ini adalah data kualitatif dan data kuantitatif yang terdiri dari: a. Data angket (kuesioner) minat belajar siswa. b. Data nilai siswa yang dapat dianalisis secara deskriptif. c. Data hasil evaluasi belajar kognitif siswa. Metode pengambilan data yang digunakan dalam penelitian ini adalah instrumen pengamatan terhadap aktivitas belajar siswa, aktivitas guru, hasil diskusi, dan tes Dari data yang diperoleh dari tiap siklus dianalisis secara deskriptif kualitatif dengan menghitung persentase ketuntasan belajar secara klasikal.

\section{HASIL DAN PEMBAHASAN}

Pada penelitian tindakan ini yang menjadi subjek adalah siswa kelas IX/2 SMP Negeri 85 Jakarta. Pertimbanganya, karena siswa di kelas tersebut masih banyak yang belum mencapai ketuntaasan belajar (KKM) serta beberapa siswa masih ada yang kurang 
termotivasi dalam belajar atau kurang berminat dalam pelajaran IPA. Hal ini disebabkan guru belum menggunakan metode dan media yang digunakan guru sacara optimal sehingga siswa merasa bosan. Hasil pemberian kuesioner pendahuluan sebelum dilakukan tindakan bahwa minat terhadap pelajaran IPA siswa masih rendah.

Tabel 1 : Minat Terhadap IPA

\begin{tabular}{llll}
\hline No & Aspek & Ya & Tidak \\
\hline 1 & Senang & 91,67 & 8,33 \\
2 & Termotivasi & 86,11 & 13,89 \\
3 & Cara Mengajar Guru & 75,00 & 25,00 \\
4 & Kesulitan & 63,89 & 36,11 \\
& Jumlah & 79,17 & 20,83 \\
\hline
\end{tabular}

Tindakan kelas yang telah dilakukan dengan memanfaatkan media Physics Courseware dapat memberikan ide atau gagasan yang lebih baik khususnya bagi para guru IPA. Berdasarkan hasil pengamatan yang dilakukan oleh pengamat, pada siklus I telah mengalami perbaikan dan peningkatan pada siklus II. Perubahan yang mengalami peningkatan meliputi;

1. Aktivitas guru diamati atau dinilai antar siklus. Hasil pengamatan terhadap aktivitas guru dalam pembelajaran di dalam kelas merupakan perbandingan hasil pengamatan terhadap aktivitas guru pada akhir tiap siklus. Hasil akhir pengamatan dan penilaian aktivitas guru pada akhir setiap siklus di tampilkan pada table berikut:

\section{Tabel 2. Hasil Pengamatan terhadap} Aktivitas Guru

\begin{tabular}{clcc}
\hline \multirow{2}{*}{ No. } & \multicolumn{1}{c}{ Indikator } & \multicolumn{2}{c}{ Keadaan Akhir } \\
\cline { 3 - 4 } & & I Siklus & \multicolumn{1}{c}{ II } \\
\hline 1 & Pembukaan & Sangat & Sangat \\
& pembelajaran & Baik & baik \\
2 & Memberikan & Baik & Baik \\
& motivasi dan & & \\
& apersepsi & & \\
3 & Menjelaskan & Sangat & Sangat
\end{tabular}

\begin{tabular}{|c|c|c|c|}
\hline & $\begin{array}{l}\text { rumusan tujuan } \\
\text { pembelajaran }\end{array}$ & Baik & baik \\
\hline 4 & Urutan pembelajaran & Baik & $\begin{array}{c}\text { Sangat } \\
\text { baik }\end{array}$ \\
\hline 5 & $\begin{array}{l}\text { Penggunaan media } \\
\text { pembelajaran }\end{array}$ & Baik & $\begin{array}{l}\text { Sangat } \\
\text { baik }\end{array}$ \\
\hline 6 & $\begin{array}{l}\text { Adanya waktu bagi } \\
\text { siswa untuk bertanya }\end{array}$ & $\begin{array}{l}\text { Sangat } \\
\text { Baik }\end{array}$ & $\begin{array}{c}\text { Sangat } \\
\text { baik }\end{array}$ \\
\hline 7 & $\begin{array}{l}\text { Interaksi siswa } \\
\text { dengan siswa }\end{array}$ & Baik & $\begin{array}{c}\text { Sangat } \\
\text { baik }\end{array}$ \\
\hline 8 & $\begin{array}{l}\text { Interaksi guru } \\
\text { dengan siswa }\end{array}$ & Baik & $\begin{array}{c}\text { Sangat } \\
\text { baik }\end{array}$ \\
\hline 9 & $\begin{array}{l}\text { Membimbing diskusi } \\
\text { siswa }\end{array}$ & $\begin{array}{l}\text { Sangat } \\
\text { Baik }\end{array}$ & $\begin{array}{c}\text { Sangat } \\
\text { baik }\end{array}$ \\
\hline
\end{tabular}

Pelaksanaan pembelajaran mengalami perbaikan atau peningkatan kualitas bagi aktivitas guru sangat baik dalam memberikan materi pelajaran secara urutan (indikator 4), sangat baik dalam menggunakan media pembelajaran (indikator 5), sangat baik dalam menjalin interaksi antar siswa (indikator 7) dan sangat baik dalam memperbaik interaksi antara siswa dan guru (indikator 8). Peningkatan perubahan aktivitas guru di atas menunjukkan bahwa penggunaan media pembelajaran yang dipillih, yaitu Physics Courseware dapat memperbaiki dan meningkatkan aktivitas guru dalam pembelajaran.

2. Aktivitas siswa diamati atau dinilai pada pertemuan dalam siklus pertama saja. Perbandingan hasil akhir pengamatan dan penilaian aktivitas siswa pada pertemuan 1 sampai dengan 3 di tampilkan pada tabel berikut:

Tabel 3 Hasil Pengamatan Aktivitas Siswa

\begin{tabular}{|c|c|c|c|c|}
\hline \multirow{2}{*}{ No. } & \multirow{2}{*}{$\begin{array}{l}\text { Aktivitas } \\
\text { Siswa }\end{array}$} & \multicolumn{3}{|c|}{ Jumlah Siswa } \\
\hline & & 1 & 2 & 3 \\
\hline 1. & $\begin{array}{l}\text { Memperhati } \\
\text { kan dengan } \\
\text { seksama } \\
\text { penjelasan } \\
\text { guru }\end{array}$ & 32 & 34 & 35 \\
\hline 2. & $\begin{array}{l}\text { Mempersiap } \\
\text { kan diri secara }\end{array}$ & 31 & 33 & 35 \\
\hline
\end{tabular}




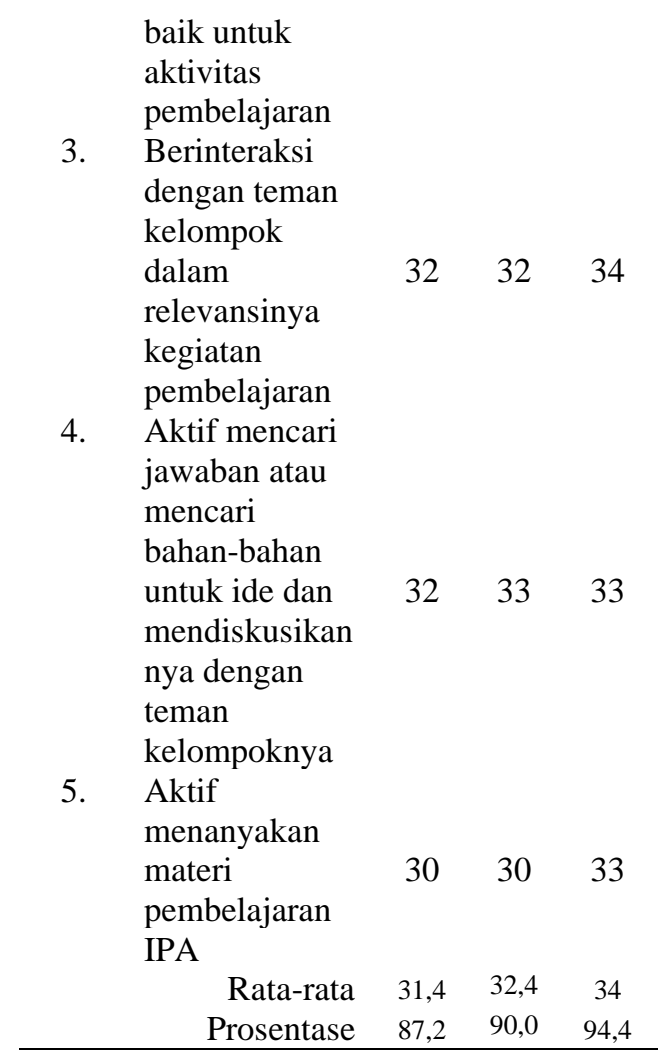

Prosentasi hasil pengamatan sudah menunjukkan hasil yang sangat baik dari $87,2 \%$ meningkat menjadi $90,0 \%$ dan akhirnya menjadi $94,4 \%$. Peningkatan prosentasi ini dirasa sudah lebih dari cukup atau sudah sangat baik. Peningkatan perubahan aktivitas siswa di atas menunjukkan bahwa penggunaan media pembelajaran yang dipilih, yaitu Physics Courseware dapat memperbaiki dan meningkatkan aktivitas siswa dalam pembelajarannya.

3. Diskusi kelompok merupakan kegiatan siswa dalam lingkungan yang heterogen. Diskusi kelompok menjadi sarana mereka dalam penguasaan materi, kemampuan penyampaian materi di depan kelas, kemampuan bekerja sama dan kemampuan menjawab pertanyaan di dalam diskusi. Berikut tabel yang menunjukkan perbandingan hasil penilaian kelompoknya setiap siklus.

\section{Tabel 4. Penilaian Diskusi Kelompok 1}

sd 6

\begin{tabular}{cccc}
\hline \multirow{2}{*}{$\begin{array}{c}\text { Kelom } \\
\text { pok }\end{array}$} & $\begin{array}{c}\text { Siklus } \\
\text { I }\end{array}$ & $\begin{array}{c}\text { Siklus } \\
\text { II }\end{array}$ & \multirow{2}{*}{$\begin{array}{c}\text { Pening } \\
\text { katan }\end{array}$} \\
\cline { 2 - 3 } & Rata2 & Rata2 & \\
\hline 1 & 80,29 & 84,17 & 3,88 \\
2 & 80,04 & 85,00 & 4,96 \\
3 & 80,02 & 84,58 & 5,56 \\
4 & 81,25 & 86,25 & 5,00 \\
5 & 80,00 & 85,42 & 5,42 \\
6 & 79,75 & 85,83 & 6,08 \\
\hline
\end{tabular}

Peningkatan nilai menunjukkan bahwa penggunaan media pembelajaran yang dipillih, yaitu Physics Courseware dapat memperbaiki dan meningkatkan kemampuan siswa dalam mampu penguasaan materi pelajaran, mampu menyampaian materinya di depan kelas, mampu bekerja sama dan mampu menjawab pertanyaan di dalam diskusi pembelajarannya

4. Kegiatan mengerjakan LKS juga salah satu kegiatan diskusi kelompok. Seperti di atas bahwa diskusi kelompok merupakan kegiatan siswa dalam lingkungan yang heterogen yang menjadikan siswa belajar menerima adanya perbedaan pendapat antar individu dalam kelompok. Hal diskusi kelompok mengerjakan LKS memberi pengalaman kepada siswa suatu LKS dikerjakan dengan lengkap, dikerjakan mandiri, dikerjakan dengan rapi, dan menjawabnya dengan tepat atau benar. Berikut tabel yang menunjukkan perbandingan hasil penilaian pengerjaan LKS kelompoknya.

Tabel 5. Hasil Penilaian Pengerjaan LKS

\begin{tabular}{llcl}
\hline \multirow{3}{*}{ Kelompok } & Siklus & Siklus & \multirow{2}{*}{ Pening } \\
\cline { 2 - 3 } & Rata 2 & Rata 2 & \multirow{2}{\text{katan}}{} \\
\cline { 2 - 3 } & & & \\
\hline
\end{tabular}




\begin{tabular}{cccc}
\hline 1 & 83,25 & 87,50 & 4,25 \\
2 & 83,33 & 87,08 & 3,75 \\
3 & 83,25 & 86,67 & 3,42 \\
4 & 84,17 & 87,92 & 3,75 \\
5 & 83,75 & 88,33 & 4,58 \\
6 & 84,79 & 87,92 & 3,13 \\
Jumlah & 502,67 & 525,42 & 22,75 \\
Rata-rata & 83,76 & 87,57 & 3,81 \\
\hline
\end{tabular}

Peningkatan tersebut menunjukkan bahwa siswa mendapat pengalaman bahwa LKS harus dikerjakan dengan lengkap, dikerjakan mandiri, dikerjakan dengan rapi, dan dijawab dengan tepat atau benar. Peningkatan nilai rata rata kelompok siswa di atas menunjukkan pula bahwa penggunaan media pembelajaran yang dipillih oleh guru, yaitu Physics Courseware dapat memperbaiki dan meningkatkan kemampuan siswa dalam mengerjakan LKS dengan lengkap, kemandirian, kerapian, dan dijawab dengan tepat atau benar.

5. Selain itu, kreativitas dan semangat siswa dalam proses pembelajaran IPA mendapat dukungan dari guru, yaitu dengan cara melakukan perubahan metode dan strategi pembelajarannya di kelas, agar siswa menjadi semangat, dan dapat mencapai ketuntasan belajar. IPA merupakan pelajaran yang harus terus menerus menuntut siswa aktif motivasi dirinya dengan mengerjakan soal-soal. Penggunaan media pembelajaran yang dipillih adalah Physics Courseware. Penggunaan media pembelajaran tersebut berdampak pada hasil belajar siswa menjadi lebih baik, yaitu peningkatan jumlah siswa yang mencapai KKM dan pencapai nilai tertinggi menjadi lebih besar yaitu nilai 100.

\section{Tabel 6. Hasil Belajar Siswa}

Hasil Kualitas $\quad$ Siklus $\quad$ Siklus

\begin{tabular}{|c|c|c|c|}
\hline & & $\mathrm{I}$ & II \\
\hline $\begin{array}{c}85-100 \\
\text { (A) }\end{array}$ & Sangat baik & 6 & 24 \\
\hline $\begin{array}{c}75-84 \\
\text { (B) }\end{array}$ & Baik & 21 & 12 \\
\hline $\begin{array}{c}65-74 \\
(\mathrm{C})\end{array}$ & Cukup & 8 & 0 \\
\hline $\begin{array}{l}55-64 \\
\text { (D) }\end{array}$ & Kurang & 1 & 0 \\
\hline \multirow[t]{3}{*}{$<54(\mathrm{E})$} & $\begin{array}{l}\text { Sangat } \\
\text { Kurang }\end{array}$ & 0 & 0 \\
\hline & Rata - rata & 78,89 & 87,50 \\
\hline & KKM (80) & 28 & 36 \\
\hline
\end{tabular}

Berdasarkan hasil evaluasi siklus II, pada tabel tersebut, diketahui bahwa siswa yang memiliki nilai yang mencapai dan lebih tinggi dari KKM (80) menjadi meningkat dan lebih baik dibandingkan dengan siklus I. Peningkatan hasil belajar menjadikan siswa yang berada pada nilai sangat baik (A) bertambah 18 orang, dan yang berada pada nilai baik (B) berkurang 9 orang, siswa yang berada pada nilai cukup (C) berkurang 8 orang, siswa yang berada pada nilai kurang (D) berkurang 1 orang, sedangkan siswa yang berada pada nilai sangat kurang (E) tidak ada. Diketahui pula bahwa ketuntasan belajar dapat tercapai berdasarkan hasil dari tes yang dilakukan pada akhir pembelajaran setiap siklus. Diperoleh hasil adanya peningkatan kompetensi terhadap nilai IPA yang diperoleh siswa. Pada siklus I rata rata nilai sebesar 78,89 masih berada dibawah KKM, sedangkan pada siklus II rata rata nilai sebesar 87,50 sudah berada diatas KKM. Pada siklus II siswa yang memiliki nilai yang diatas KKM menjadi sebanyak 36 orang $(100 \%)$. Berdasarkan pembahasan atau uraian diatas pelaksanaan tindakan dan hasil pengamatan, maka dengan menerapkan media Physics Courseware dalam pembelajaran guru dapat memperbaiki proses pembelajaran dan hasil belajar siswa.

Most of the interactive multimedia 
developed so far are used to improve students' cognitive skill. In Indonesia, the interactive multimedia is mostly created for mathematics, physics, biology, language, chemistry, and engineering subjects [15]. Ada banyak media serta metode yang dapat digunakan dalam kegiatan pembelajaran, diantaranya adalah dengan bermain [16]. Minat merupakan salah satu faktor penentu dalam keberhasilan pendidikan. Seorang peserta didik akan berhasil dalam pelajarannya apabila dalam diri peserta didik itu ada keinginan untuk belajar [17]. Selain itu untuk membangkitkan dan mengembangkan minat belajar secara terus menerus, siswa dapat melakukannya dengan menentukan/ mengetahui tujuan belajar yang hendak dicapai, menanggapi secara positif pujian/ dorongan dari orang lain, menentukan target/sasaran penyelesaian tugas belajar dan perilaku sejenis lainnya [18]. Selain minat belajar, model pembelajaran juga mempengaruhi hasil belajar fisika [19]. Berdasarkan riset yang telah dilakukan maka hal ini sejalan dengan hasil riset yang telah dilakukan bahwa minat dah hasil belajar meningkat ketika diberikan treatmen pembelajaran dengan menggunakan pembelajaran physic courseware.

\section{SIMPULAN}

Tujuan dasar dari penelitian tindakan kelas ini adalah untuk mengetahui keberhasilan proses $\mathrm{KBM}$ dalam meningkatkan minat dan hasil belajar siswa melalui penggunaan media Physics Courseware pada siswa kelas IX tahun 2016/2017 pada materi fisika listrik dinamis. Dari hasil pelaksanaan tindakan kelas, evaluasi, dan pembahasan dapat disimpulkan dalam dua aspek bagi guru dan siswa; 1). Bagi guru, penggunaan media Physics Courseware dapat memperbaiki dan meningkatkan aktivitas dalam membuka pelajaran, pemberian motivasi dan appersepsi, lebih mudah dan tepat dalam menyusun rumusan tujuan pembelajaran, simpel dalam mendesain urutan pembelajaran, efektif dalam penggunaan media pembelajaran, tepat dalam memberikan waktu bagi siswa untuk bertanya, jeli dalam memperbaiki interaksi antar siswa dengan siswa, siswa dengan guru, dan luwes dalam membimbing siswa dalam berdiskusi dalam pembelajaran. 2).

Bagi siswa, penggunaan media Physics Courseware : a). Dapat meningkatkan aktivitas siswa dalam belajar $(94,44 \%)$ seperti ; memperhatikan dengan seksama penjelasan guru; mempersiapkan diri secara baik untuk aktivitas pembelajaran; berinteraksi dengan teman kelompok dalam relevansinya kegiatan pembelajaran; keaktifan mencari jawaban atau mencari bahan-bahan untuk ide dan mendiskusikannya dengan teman kelompoknya; dan secara aktif menanyakan materi pembelajaran IPA, b). Dapat meningkatkan nilai diskusi kelompok seperti kamampuan siswa dalam penguasaan materi pelajaran, kemampuan menyampaian materinya di depan kelas, kemampuan bekerja sama dan mampu menjawab pertanyaan di dalam diskusinya, c). Dapat meningkatkan hasil penilaian dalam mengerjakan LKS seperti; LKS harus dikerjakan dengan lengkap, dikerjakan mandiri, dikerjakan dengan rapi, dan dijawab dengan tepat atau benar, d). Dapat meningkatkan hasil belajar. Pada siklus I terdapat 28/36 siswa nilai rata rata 78,89 yang belum mencapai KKM, lalu pada siklus II semua siswa 36/36 dengan nilai rata rata 87,50 sudah mencapai KKM artinya memberikan hasil yang sangat baik. Merangkum dari perencanaan, pelaksanaan, pengamatan, refleksi, hasil tindakan dan pengamatan yang dilakukan, didukung juga oleh pengolahan data yang sederhana dapat dijelaskan bahwa pengunaan media physics 
courseware sebagai media pembelajaran dapat meningkatkan aktivitas guru, aktivitas siswa dalam kelompok, aktivitas siswa dalam mengerjakan LKS, dan dapat meningkatkan hasil belajar siswa. Dengan demikian dapat disimpulkan bahwa pemanfaatan media physics courseware sebagai media pembelajaran fisika dapat meningkakan minat dan hasil belajar siswa pada materi arus listrik.

\section{DAFTAR PUSTAKA}

[1] N. Purwanto, Psikologi Pendidikan. Bandung: Rosda Karya, 2000.

[2] Tarjuki, "Pembelajaran Fisika Dengan Model Pembelajaran Kooperatf Tipe STAD Dengan Mengurangi Miskonsepsi Siswa Pada Pokok Bahasan Rangkaian Arus Listrik Siswa Sma1 Ksatrian Kelas 1 Semester 2 Tahun Ajaran 2005/2006," UNNES, 2007.

[3] F. Syukur, Teknologi Pendidikan. Semarang: Rasail, 2005.

[4] Harjanto, Perencanaan Pengajaran. Jakarta: Rineka Cipta, 2000.

[5] Slameto, Belajar dari Faktor-faktor yang Mempengaruhinya. Jakarta: Rineka Cipta, 2003.

[6] N. Purwanto, Psikologi Pendidikan. Bandung: Remaja Rosda Karya, 2000.

[7] A. Arsyad, Media Pembelajaran. Jakarta: PT. Raja Grafindo Persada, 2005.

[8] S. B. D. dan A. Zain, Strategi Belajar Mengajar. Jakarta: Rineka Cipta, 2006.

[9] D. Arief. S. Sadiman, Media pendidikan, Pengertian, Pengembangan dan pemanfaatannya. PT. Raja Grafindo Persada, 2006.

[10]A. dan M. B. Usman, Media Pembelajaran. Jakarta: Ciputat Press, 2002.

[11]W. Sanjaya, Strategi Pembelajaran. Jakarta: Kencana, 2008.
[12]A. Rohani, Media Instruksional Edukatif. Jakarta: Rineka Cipta, 1997.

$[13] \mathrm{K}$. Lee, "Barriers to the Use of Computer-assisted Language Learning 2000," vol. Vol. VI, N, 2000.

[14]N. Sudjana, Penilaian Hasil Proses Belajar Mengajar. Jakarta: Rosda Karya, 1999.

[15] A. nisa N. S. Indah Septiani, I. Septiani, T. Rejekiningsih, Triyanto, and Rusnaini, "Development of interactive multimedia learning courseware to strengthen students' character," Eur. J. Educ. Res., vol. 9, no. 3, pp. 12671279, 2020, doi: 10.12973/eujer.9.3.1267.

[16]D. Yulianti, M. Lestari, and A. Yulianto, "Penerapan Jigsaw Puzzle Competition Dalam Pembelajaran Kontekstual Untuk Meningkatkan Minat Dan Hasil Belajar Fisika Siswa Smp," J. Pendidik. Fis. Indones., vol. 6, no. 2, pp. 84-89, 2010, doi: 10.15294/jpfi.v6i2.1118.

[17] S. P. Astuti, "Pengaruh Kemampuan Awal Dan Minat Belajar," J. Form., vol. 5, no. 1, pp. 68-75, 2015, [Online]. Available:

http://journal.lppmunindra.ac.id/index. php/Formatif/article/viewFile/167/160

[18] Supardi, L. Leonard, H. Suhendri, and Rismurdiyati, "Pengembangan Media Pembelajaran dan Minat Belajar Terhadap Hasil Belajar Fisika," $J$. Form., vol. 2, no. 1, pp. 71-81, 2012, [Online]. Available: http://journal.lppmunindra.ac.id/index. php/Formatif/article/view/86/84.

[19]L. Charli, T. Ariani, and L. Asmara, "Hubungan Minat Belajar terhadap Prestasi Belajar Fisika," Sci. Phys. Educ. J., vol. 2, no. 2, pp. 52-60, 2019, doi: $10.31539 /$ spej.v2i2.727. 